\title{
Severe diaphragm weakness in multiple sclerosis
}

\author{
CB COOPER, P St J TREND, CM WILES \\ From the Departments of Medicine and Neurology, St Thomas's Hospital, London
}

Respiratory failure is only rarely associated with multiple sclerosis. ${ }^{12}$ We describe a patient in whom a diagnosis of demyelinating disease was established and who presented in relapse with acute bilateral diaphragm weakness associated with other signs suggestive of a lesion extending up to the cervicomedullary junction. He developed respiratory failure and required mechanical ventilation.

\section{Case report}

A 41 year old caucasian male presented in February 1981 with vertigo, diplopia, paraesthesiae, and urinary retention. He was ataxic and had an internuclear ophthalmoplegia and bilateral extensor responses. Lumbar cerebrospinal fluid showed 41 lymphocytes $/ \mathrm{mm}^{3}$ and a protein concentration of $2 \mathrm{~g} / \mathrm{l}$. He was treated with dexamethasone and recovered. In March 1982 he presented with typical left optic neuritis responding poorly to corticosteroid treatment. Later that year he had sensory disturbance over the trunk and gait ataxia. In May 1983 he developed

Address for reprint requests: Dr CB Cooper, Respiratory Function Unit, Lodge Moor Hospital, Sheffield S10 4LH.

Accepted 3 June 1985 weakness of the right arm and leg associated with burning paraesthesiae, which spread up the back of the head. Reduced pinprick sensation was noted over the maxillary and mandibular divisions of the fifth cranial nerve and there was weakness and wasting of the right shoulder abductors.

He was admitted in February 1984 with a six day history of dull, burning retro-orbital pain extending to the vertex. On the day of admission he had woken at 4 am unable to breathe lying flat and had then developed numbness and weakness of his right hand and hesitancy of micturition. On examination he had an ataxic gait and left sided optic atrophy. There was mild spastic quadriparesis with extensor plantar responses. Pain and temperature sensations were reduced in the ophthalmic divisions of the right and left trigeminal nerves, from $\mathrm{C} 2$ to $\mathrm{T} 5$ on the right and from $\mathrm{C2}$ to $\mathrm{C5}$ on the left. In addition there was a disturbance of pain and temperature sensation below $\mathrm{T} 4$ bilaterally with impaired joint position sense in both feet and the right hand. He was breathless at rest with a respiratory rate of 20 breaths a minute and he used his accessory muscles of respiration. There was considerable paradoxical abdominal wall movement. His vital capacity was 2.01 standing and 0.91 supine. When he was breathing $24 \%$ oxygen the arterial oxygen concentration $\left(\mathrm{PaO}_{2}\right)$ was $72 \mathrm{~mm} \mathrm{Hg}(9.6 \mathrm{kPa})$
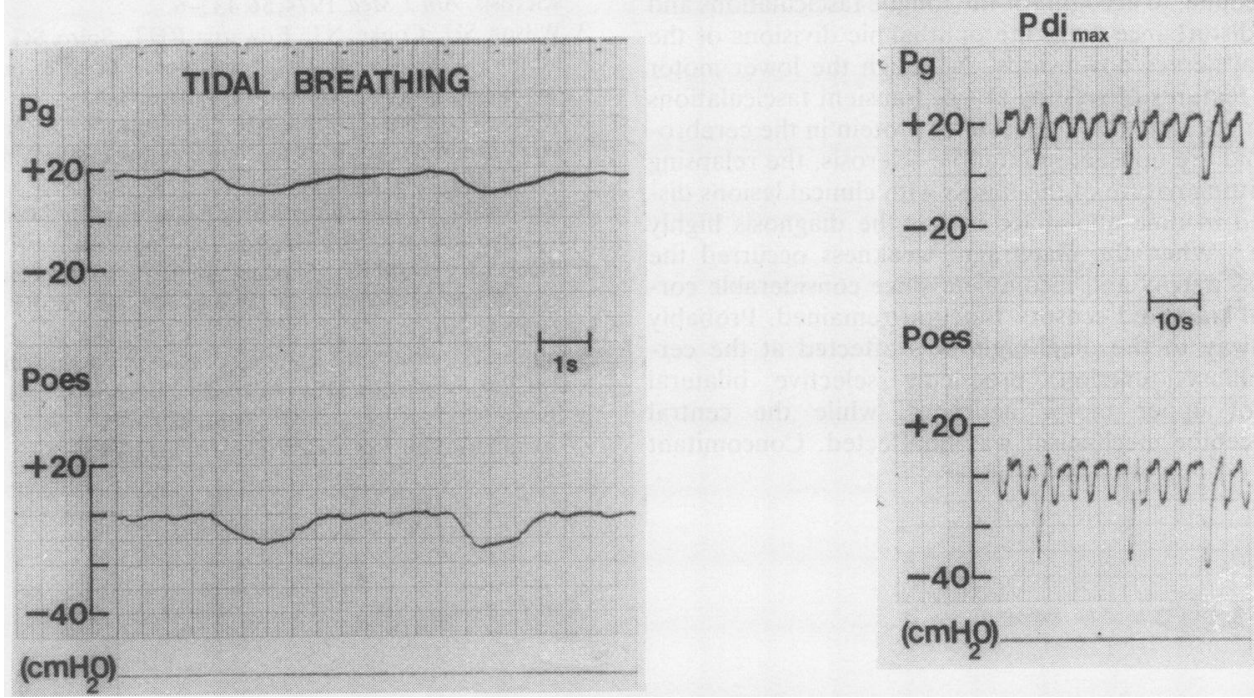

Gastric pressure $(P g)$ and oesophageal pressure (Poes) during tidal breathing and during maximal inspiration against an occluded airway (Pdi max $)$. 
and carbon dioxide tension $\left(\mathrm{PaCO}_{2}\right) 28 \mathrm{~mm} \mathrm{Hg}(3.7 \mathrm{kPa})$. A chest radiograph was normal.

Maximal static inspiratory and expiratory mouth pressures were normal $\left(\mathrm{Pi}_{\max } 73 \mathrm{~cm} \mathrm{H}_{2} \mathrm{O}, \mathrm{Pe}_{\max } 170 \mathrm{~cm} \mathrm{H}_{2} \mathrm{O}\right){ }^{3}$ Transdiaphragmatic pressure (Pdi) was recorded with balloon tipped catheters in the stomach and oesophagus. No. gradient developed during tidal breathing, changes in oesophageal (that is, pleural) pressure being exactly mirrored by changes in gastric pressure (figure). Pdi was reduced during a maximal inspiratory effort against an occluded airway $\left(\mathrm{Pdi}_{\max } 19 \mathrm{~cm} \mathrm{H}_{2} \mathrm{O}\right.$ ), during a maximal inspiration to TLC ( $\left.\mathrm{Pdi}_{\mathrm{TLC}} 6 \mathrm{~cm} \mathrm{H}_{2} \mathrm{O}\right)$ and also during a maximal sniff ( $\left.\mathrm{Pdi}_{\text {sniff }} 8 \mathrm{~cm} \mathrm{H}_{2} \mathrm{O}\right) \cdot{ }^{4} \mathrm{~A}$ diagnosis of diaphragm weakness was made. Rebreathing $5 \%$ carbon dioxide with $50 \%$ oxygen increased minute ventilation.

He was treated with intravenous methylprednisolone. Fifteen days after admission he developed further weakness of the legs and became more breathless. A chest radiograph showed right lower lobe collapse. When he was breathing $24 \%$ oxygen his $\mathrm{PaO}_{2}$ was $47 \mathrm{~mm} \mathrm{Hg}(6.3 \mathrm{kPa})$ and $\mathrm{PaCO}_{2} 44 \mathrm{~mm} \mathrm{Hg}(6.2 \mathrm{kPa})$. $\mathrm{Pdi}_{\max }$ was $16 \mathrm{~cm} \mathrm{H} \mathrm{H}_{2} \mathrm{O}$,

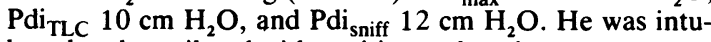
bated and ventilated with positive and expiratory pressure, and later a tracheostomy was performed. At this stage he was noted to have bilateral fasciculation of the tongue but no other evidence of bulbar dysfunction. Twelve weeks later he could manage without ventilatory support and was able to sleep in the sitting position. $\mathrm{Pi}_{\max }$ was $26 \mathrm{~cm} \mathrm{H}_{2} \mathrm{O}$,

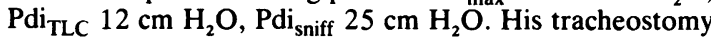
was closed. Subsequently he improved and returned to work.

\section{Discussion}

The patient we describe presumably had a plaque of demyelination affecting the high cervical cord and later the lower medulla, to account for the tongue fasciculations and sensory disturbance from the ophthalmic divisions of the trigeminal nerves downwards. Although the lower motor neurone features of wasting at $\mathrm{C5}$, transient fasciculations of the tongue, and the high level of protein in the cerebrospinal fluid are unusual in multiple sclerosis, the relapsing and remitting nature of the illness with clinical lesions disseminated in time and space makes the diagnosis highly probable. ${ }^{5}$ When the diaphragm weakness occurred the lesion was patchy and incomplete since considerable corticospinal tract and sensory function remained. Probably the pathway to the diaphragm was affected at the cervicomedullary junction, producing selective bilateral lesions of upper motor neurones, while the central chemoreceptor mechanism was unaffected. Concomitant disease of the lower motor neurones at C3-5 cannot be excluded. We are not aware that such a lesion has previously been described in demyelinating disease. Four patients with diagnoses of multiple sclerosis are reported to have developed painless dyspnoea, tachypnoea, and diminished chest wall movement.' Vital capacities and arterial oxygen saturation were reduced but diaphragm function was not assessed.

Maximum static mouth pressures are frequently abnormal in patients with generalised neuromuscular disturbance $^{6}$ but there can be considerable loss of inspiratory muscle force before volume changes become apparent.' In this case mouth pressures could be measured reliably only before tracheostomy yet at this time, when transdiaphragmatic pressures were lower, $\mathrm{Pe}_{\max }$ and $\mathrm{Pi}_{\max }$ remained normal, reflecting the action of the accessory respiratory muscles.

Severe diaphragm weakness is associated with hypercapnic respiratory failure, ${ }^{8}$ which is due not only to respiratory muscle weakness but also to mechanical factors that increase the work of breathing. Weakness of the diaphragm is often unrecognised in neurological disease. Careful evaluation of respiratory function may contribute to its diagnosis and to assessment of progress and response to treatment.

\section{References}

1 Guthrie TC, Kurtzke JF, Berlin L. Acute respiratory failure in multiple sclerosis and its management. Ann Intern Med 1952;37: 1197-203.

2 Rizvi SS, Ishinkawa S, Faling JL, Schlessinger L, Satia J, Seckel B. Defect in automatic respiration in a case of multiple sclerosis. Am J Med 1974;56:433-6.

3 Wilson SH, Cooke NT, Edwards RHT, Spiro SG. Predicted normal values for maximal respiratory pressures in caucasian adults and children. Thorax 1984;39:535-8.

4 Gibson GJ, Clark E, Pride NB. Static transdiaphragmatic pressures in normal subjects and chronic hyperinflation. Am Rev Respir Dis 1981;124:685-9.

5 McDonald WI, Halliday AM. Diagnosis and classification of $O$ multiple sclerosis. Br Med Bull 1977;33:4-9.

6 Black LE, Hyatt RE. Maximal static respiratory pressures in $\frac{D}{0}$ generalised neuromuscular disease. Am Rev Respir Dis 1971; 103: 641-50.

7 Gibson GJ, Pride NB. Lung mechanics in diaphragm paralysis. Am Rev Respir Dis 1979;119:119-20.

8 Braun NMT. Rochester DF. Muscular weakness and respirat- N ory failure. Am Rev Respir Dis 1979;119:123-5. 